\title{
Voltammetric Determination of Binding Constant and Stoichiometry of Albumin (Human, Bovine, Ovine)-Drug Complexes
}

Davide Ravelli, ${ }^{a}$ Paola Isernia,${ }^{b}$ Andrea Acquarulo, ${ }^{a}$ Antonella Profumo, ${ }^{a}$ Daniele Merli ${ }^{a, *}$

\begin{abstract}
${ }^{a}$ Università degli Studi di Pavia, Dipartimento di Chimica, Viale Taramelli 12, 27100 Pavia, Italia. E-mail: daniele.merli@unipv.it

${ }^{\mathrm{b}}$ Fondazione IRCCS Policlinico San Matteo, Servizio di Immunoematologia e Medicina Trasfusionale, Centro Lavorazione e Validazione Emocomponenti (CLV), Viale Camillo Golgi 19, 27100 Pavia, Italia
\end{abstract}

\section{Supporting Information}




\section{S.1 Materials and Methods}

Electrochemical measurements were performed on a BASi voltammetric station (CGME; BASi, 2701 Kent Avenue West Lafayette, IN 47906 USA) controlled with a BASi Epsilon EC 2000 software. A $20 \mathrm{~mL}$ voltammetric cell was used, equipped with a $3 \mathrm{~mm}$ diameter glassy carbon (BASI) as working electrode, a platinum wire as counter electrode and a $\mathrm{BASi} \mathrm{Ag} / \mathrm{AgCl} / 3 \mathrm{M} \mathrm{NaCl} \mathrm{NaCl}$ reference electrode $(\mathrm{E}=+0.197 \mathrm{~V}$ vs NHE).

As a supporting electrolyte, $\mathrm{NaCl} 0.9 \%$ was used.

All the reagents used were of the purest grade available and obtained from Sigma Aldrich or Carlo Erba. BSA was obtained from Sigma Aldrich (lyophilized powder, $\geq 96 \%$, agarose gel electrophoresis) and OVA (>98\%) from Carlo Erba. Human serum was obtained from Policlinico San Matteo, Pavia. Total protein content in human serum was $42 \mathrm{~g} \cdot \mathrm{L}^{-1}$, as determined by standard clinical serum electrophoresis procedure. Alpha globulins $(\alpha 1+\alpha 2)$ were $7 \mathrm{~g} \cdot \mathrm{L}^{-1}$, beta globulins 6.2 $\mathrm{g} \cdot \mathrm{L}^{-1}$ and gamma globulins $7.5 \mathrm{~g} \cdot \mathrm{L}^{-1}$.

The dilution of human serum to the required final concentration has been performed by considering a medium molecular weight equal to the molar mass of human serum albumin (66.5 kDA).

The drugs used in this study were obtained from Merck Sigma-Aldrich, Merck KGaA, Darmstadt, Germany or from Fagron Italia s.r.l. (Bologna, Italy), and were API grade (according to European Pharmacopoeia).

\section{S.2 Analytical Procedure}

In the following, the different steps required for the acquisition of the data necessary for the characterization of each drug are reported. Before each measurement, the working electrode was polished with alumina slurry $(10 \mu \mathrm{m})$ and distilled water.

The determination of all the values of complexation constant, stoichiometry, etc. was repeated 5 times, and the reported values represent the mean value of these replicates. The relative standard deviation is $\pm 10 \%$ of the reported values. The medium values were then used in the calculations.

\section{S.3 Determination of the Albumin-Drug Complexation Constants and the Stoichiometry of Complexes}

The experimental procedure for the determination of the albumin-drug complexation constants and the stoichiometry of complexes requires the following steps: 
- the voltammetric calibration curve of the chosen drug in $\mathrm{NaCl} 0.9 \%$ is registered; typically, the employed drug concentrations $\left(\mathrm{C}_{\mathrm{DRUG}}\right)$ are in the $2 \cdot 10^{-5}-2 \cdot 10^{-4} \mathrm{M}$ range. The resulting linear plot ITD vs $\mathrm{C}_{\mathrm{DRUG}}$ is obtained, where TD stands for "total drug".

- analogously, a voltammetric calibration curve with the same aliquots of drug $\left(\mathrm{C}_{\text {DRUG }}\right)$ is registered in the presence of the supporting electrolyte and a fixed amount of albumin $\left(\mathrm{C}_{\mathrm{ALB}}\right)$, in defect with respect to the drug itself (e.g. we operate with an albumin concentration of $10^{-6} \mathrm{M}$ ). The resulting linear plot $\mathrm{I}_{\mathrm{FD}}$ vs $\mathrm{C}_{\mathrm{DRUG}}$ is obtained, where FD stands for "free drug".

In the following, we report two exemplificative cases, where the treatments for the single complex or multiple complexes formation apply, respectively. The first part of the treatment is in common.

As an example, we report the results obtained for the case of ketoprofen with OVA. The following graph (Figure S1) can be obtained (the corresponding values are gathered in Table S1 below):

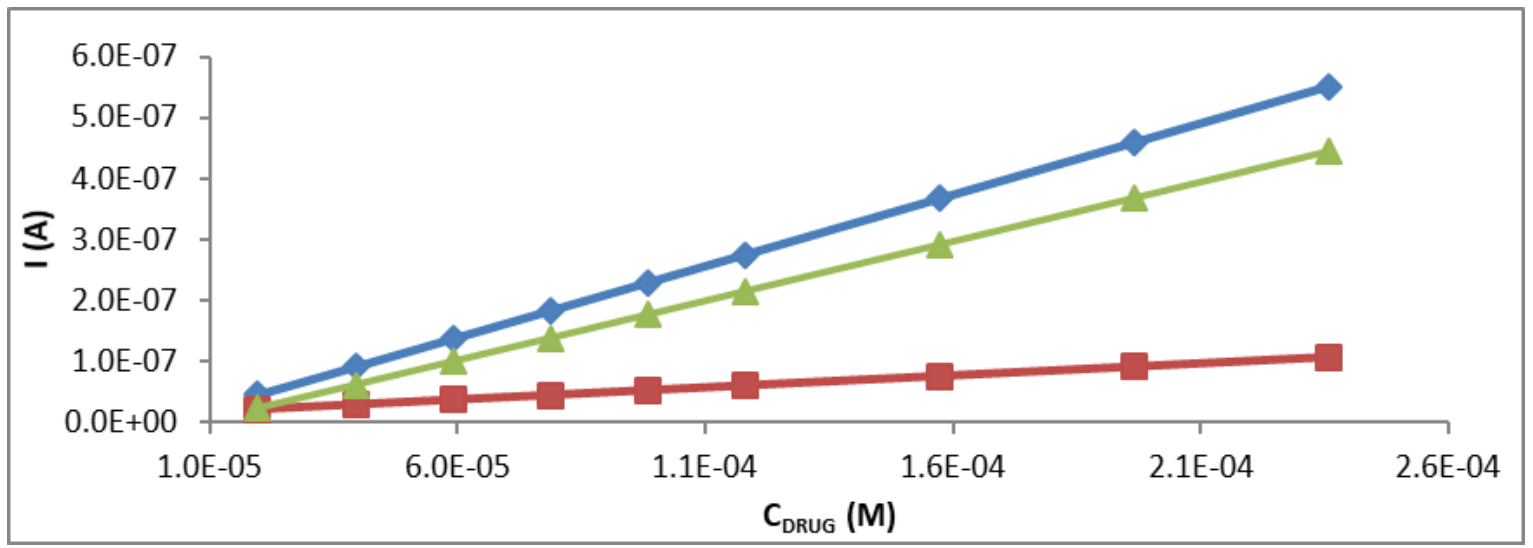

Figure S1. Relationship of peak current vs drug concentration for ketoprofen and a) no albumin, NaCl 0.9\% (ITD, blue color); b) albumin $\left(\mathrm{OVA}, 100 \mathrm{mg} \cdot \mathrm{L}^{-1}\right)+\mathrm{NaCl} 0.9 \%\left(\mathrm{I}_{\mathrm{FD}}\right.$, red color); c) punctual difference between the values of $\mathrm{I}_{\mathrm{TD}}$ and $\mathrm{I}_{\mathrm{FD}}\left(\Delta \mathrm{I}=\mathrm{I}_{\mathrm{TD}}\right.$ $-\mathrm{I}_{\mathrm{FD}}$, green color). 
Table S1. Values used for the construction of the plots in Figure S1. ITD values: calibration curve of the drug in $0.9 \%$ NaCl; IFD values: calibration curve in the presence of albumin. $\Delta \mathrm{I}$ values: data obtained by taking the punctual difference between $\mathrm{ITD}$ and IFD.

\begin{tabular}{|c|c|c|c|}
\hline \multirow{2}{*}{$\begin{array}{c}\text { Ketoprofen } \\
\mathbf{C}_{\mathbf{D R U G}}(\mathbf{M})\end{array}$} & $\boldsymbol{I}_{\mathrm{TD}}$ & $\boldsymbol{I}_{\mathrm{FD}}$ & $\Delta I=\boldsymbol{I}_{\mathrm{TD}}-\boldsymbol{I}_{\mathrm{FD}}$ \\
\cline { 2 - 4 } & $(\mathbf{A})$ & $(\mathbf{A})$ & $(\mathbf{A})$ \\
\hline $1.97 \mathrm{E}-05$ & $4.57 \mathrm{E}-08$ & $2.19 \mathrm{E}-08$ & $2.38 \mathrm{E}-08$ \\
\hline $3.93 \mathrm{E}-05$ & $9.17 \mathrm{E}-08$ & $2.97 \mathrm{E}-08$ & $6.20 \mathrm{E}-08$ \\
\hline $5.90 \mathrm{E}-05$ & $1.38 \mathrm{E}-07$ & $3.74 \mathrm{E}-08$ & $1.00 \mathrm{E}-07$ \\
\hline $7.87 \mathrm{E}-05$ & $1.84 \mathrm{E}-07$ & $4.51 \mathrm{E}-08$ & $1.39 \mathrm{E}-07$ \\
\hline $9.83 \mathrm{E}-05$ & $2.30 \mathrm{E}-07$ & $5.29 \mathrm{E}-08$ & $1.77 \mathrm{E}-07$ \\
\hline $1.18 \mathrm{E}-04$ & $2.76 \mathrm{E}-07$ & $6.06 \mathrm{E}-08$ & $2.15 \mathrm{E}-07$ \\
\hline $1.57 \mathrm{E}-04$ & $3.68 \mathrm{E}-07$ & $7.61 \mathrm{E}-08$ & $2.91 \mathrm{E}-07$ \\
\hline $1.97 \mathrm{E}-04$ & $4.60 \mathrm{E}-07$ & $9.16 \mathrm{E}-08$ & $3.68 \mathrm{E}-07$ \\
\hline $2.36 \mathrm{E}-04$ & $5.51 \mathrm{E}-07$ & $1.07 \mathrm{E}-07$ & $4.44 \mathrm{E}-07$ \\
\hline
\end{tabular}

The curves reported in Figure S1 have been obtained by taking the average of five different replicates of the voltammetric analysis. In particular, the parameters of intercept and slope of the experimental curves obtained from the single analyses have been averaged and used to build the plots reported in Figure S1, according to the data in Table S1.

As detailed in the mathematic procedure described in the main text, the following equation (1) results, where $\beta_{S}$ and $m$ represent, respectively, the affinity constant and the stoichiometry of the albumindrug complex:

$$
\Phi=\log \left(\frac{\Delta I}{\Delta I_{\max }-\Delta I}\right)=\log \beta_{s}+m \log [\mathrm{FD}]
$$

By plotting $\Phi=\log \left(\frac{\Delta I}{\Delta I_{\max }-\Delta I}\right)$ vs $\log [\mathrm{FD}]$, a new curve is obtained and two different scenarios can apply. If the relationship $\Phi$ vs $\log [\mathrm{FD}]$ is linear, a single complex between the drug and albumin is formed at the drug/albumin concentratio ratios explored, and the data can be processed as described in section S 3.1. On the other hand, if the relationship is NOT linear, multiple complexes with different stoichiometry are formed, and the data can be processed as described in section S 3.2. Table S2 gathers the data obtained from the manipulation of the values in Table S1, referred to the case of complex formation between ketoprofen and OVA. The corresponding $\Phi$ vs $\log [\mathrm{FD}]$ plot is reported in Figure 2 of the main text. 
Table S2. Data employed for the determination of the function $\Phi$ and for the construction of the plot $\Phi$ vs $\log [$ FD] in the case of the ketoprofen-OVA complex; these data results from the manipulation of those reported in Table S1.

\begin{tabular}{|c|c|c|c|c|}
\hline $\begin{array}{c}\mathrm{C}_{\text {DRUG }} \\
(\mathrm{M})\end{array}$ & $\begin{array}{c}{[\mathrm{FD}]^{\mathrm{a}}}_{(\mathrm{M})} \\
1.97 \mathrm{E}-05\end{array}$ & $\begin{array}{c}\log [\mathrm{FD}] \\
(\mathrm{M})\end{array}$ & $\begin{array}{c}\Delta I \\
(\mathrm{~A})\end{array}$ & $\Phi$ \\
\hline $3.93 \mathrm{E}-05$ & $9.48 \mathrm{E}-06$ & -5.02 & $2.38 \mathrm{E}-08$ & -1.25 \\
\hline $5.90 \mathrm{E}-05$ & $1.28 \mathrm{E}-05$ & -4.89 & $6.20 \mathrm{E}-08$ & -0.79 \\
\hline $7.87 \mathrm{E}-05$ & $1.61 \mathrm{E}-05$ & -4.79 & $1.00 \mathrm{E}-07$ & -0.54 \\
\hline $9.83 \mathrm{E}-05$ & $1.94 \mathrm{E}-05$ & -4.71 & $1.39 \mathrm{E}-07$ & -0.34 \\
\hline $1.18 \mathrm{E}-04$ & $2.27 \mathrm{E}-05$ & -4.64 & $1.77 \mathrm{E}-07$ & -0.18 \\
\hline $1.57 \mathrm{E}-04$ & $3.60 \mathrm{E}-05$ & -4.58 & $2.15 \mathrm{E}-07$ & -0.03 \\
\hline $1.97 \mathrm{E}-04$ & $3.93 \mathrm{E}-05$ & -4.49 & $2.91 \mathrm{E}-07$ & 0.28 \\
\hline $2.36 \mathrm{E}-04$ & $4.59 \mathrm{E}-05$ & -4.41 & $3.68 \mathrm{E}-07$ & 0.68 \\
\hline
\end{tabular}

a The concentration of free drug (FD) has been evaluated by considering the calibration curve obtained in the absence of albumin.

\section{S.3.1 Single Complex Theory}

The above discussion is general and independent from the number of albumin-drug complexes formed in solution. If a single complex is formed, the relationship $\Phi$ vs $\log [\mathrm{FD}]$ is linear, as depicted for the case of ketoprofen and OVA reported in Figure 2 of the main text (the data used in this case are reported in Tables S1 and S2). Thus, the slope of the line gives the stoichiometry ( $m$, this value has to be approximated to the nearest integer) of the complex, while the intercept corresponds to the logarithm of the complexation constant $\left(\log \beta_{\mathrm{S}}\right)$ of the complex.

\section{S.3.2 Multiple Complex Theory}

We hereby present a different situation, where the formation of multiple complexes has been observed, namely the case involving ketoprofen and HS. The following graph (Figure S2) gathers the voltammetric calibration curves obtained, as indicated above (the corresponding values are gathered in Table S3 below). 


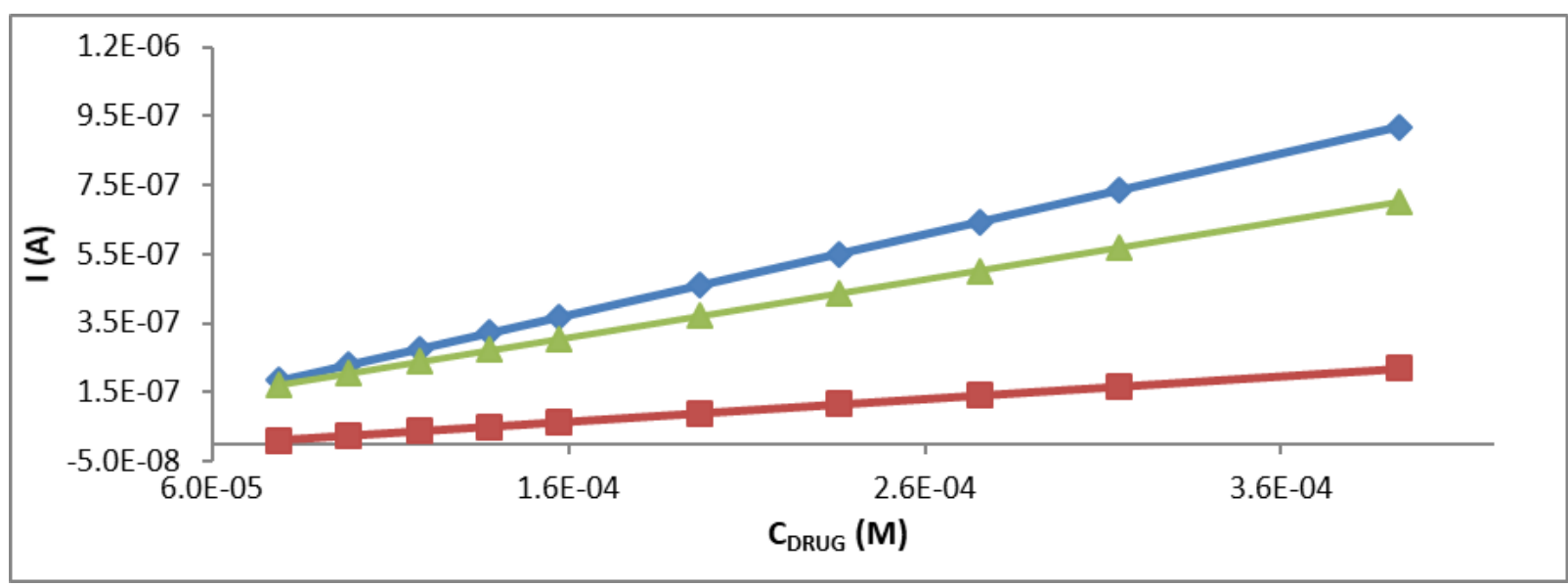

Figure S2. Relationship of peak current vs drug concentration for ketoprofen and a) no albumin, NaCl 0.9\% (ITD, blue color); b) albumin ( $\left.\mathrm{HS}, 100 \mathrm{mg} \cdot \mathrm{L}^{-1}\right)+\mathrm{NaCl} 0.9 \%\left(I_{\mathrm{FD}}\right.$, red color); c) punctual difference between the values of $\mathbf{I}_{\mathrm{TD}}$ and $\mathbf{I}_{\mathrm{FD}}\left(\Delta \mathrm{I}=\mathrm{I}_{\mathrm{TD}}-\right.$ IFD, green color).

Table S3. Values used for the construction of the plots in Figure S2. ITD values: calibration curve of the drug in $0.9 \% \mathrm{NaCl}$; $\mathrm{I}_{\mathrm{FD}}$ values: calibration curve in the presence of albumin. $\Delta \mathrm{I}$ values: data obtained by taking the punctual difference between $I_{\mathrm{TD}}$ and IFD.

\begin{tabular}{|c|c|c|c|}
\hline \multirow{2}{*}{$\begin{array}{c}\text { Ketoprofen } \\
\mathbf{C}_{\text {Drug }}(\mathbf{M})\end{array}$} & $\boldsymbol{I}_{\mathrm{TD}}$ & $\boldsymbol{I}_{\mathrm{FD}}$ & $\Delta I=\boldsymbol{I}_{\mathrm{TD}}-\boldsymbol{I}_{\mathrm{FD}}$ \\
\cline { 2 - 4 } & $\mathbf{( A )}$ & $\mathbf{( A )}$ & $(\mathbf{A})$ \\
\hline $7.87 \mathrm{E}-05$ & $1.84 \mathrm{E}-07$ & $1.02 \mathrm{E}-08$ & $1.73 \mathrm{E}-07$ \\
\hline $9.83 \mathrm{E}-05$ & $2.30 \mathrm{E}-07$ & $2.33 \mathrm{E}-08$ & $2.06 \mathrm{E}-07$ \\
\hline $1.18 \mathrm{E}-04$ & $2.76 \mathrm{E}-07$ & $3.64 \mathrm{E}-08$ & $2.39 \mathrm{E}-07$ \\
\hline $1.38 \mathrm{E}-04$ & $3.22 \mathrm{E}-07$ & $4.95 \mathrm{E}-08$ & $2.72 \mathrm{E}-07$ \\
\hline $1.57 \mathrm{E}-04$ & $3.68 \mathrm{E}-07$ & $6.26 \mathrm{E}-08$ & $3.05 \mathrm{E}-07$ \\
\hline $1.97 \mathrm{E}-04$ & $4.60 \mathrm{E}-07$ & $8.88 \mathrm{E}-08$ & $3.71 \mathrm{E}-07$ \\
\hline $2.36 \mathrm{E}-04$ & $5.51 \mathrm{E}-07$ & $1.15 \mathrm{E}-07$ & $4.36 \mathrm{E}-07$ \\
\hline $2.75 \mathrm{E}-04$ & $6.43 \mathrm{E}-07$ & $1.41 \mathrm{E}-07$ & $5.02 \mathrm{E}-07$ \\
\hline $3.15 \mathrm{E}-04$ & $7.35 \mathrm{E}-07$ & $1.67 \mathrm{E}-07$ & $5.68 \mathrm{E}-07$ \\
\hline $3.93 \mathrm{E}-04$ & $9.19 \mathrm{E}-07$ & $2.20 \mathrm{E}-07$ & $7.00 \mathrm{E}-07\left(\Delta I_{\max }\right)$ \\
\hline
\end{tabular}

The curves reported in Figure S2 have been obtained by taking the average of five different replicates of the voltammetric analysis. In particular, the parameters of intercept and slope of the experimental curves obtained from the single analyses have been averaged and used to build the plots reported in Figure S2, according to the data in Table S3.

As detailed in the mathematic procedure described in the main text and already reported above, the relationship $\Phi$ vs $\log [\mathrm{FD}]$ can be built, leading in this case to a NON linear dependence. Table S4 gathers the data obtained from the manipulation of the values in Table S3, referred to the case of complex formation between ketoprofen and HS. The corresponding $\Phi$ vs $\log [\mathrm{FD}]$ plot is reported in Figure 3 of the main text. 
Table S4. Data employed for the determination of the function $\Phi$ and for the construction of the plot $\Phi$ vs $\log [$ FD] in the case of the ketoprofen-HS complex; these data results from the manipulation of those reported in Table S3.

\begin{tabular}{|c|c|c|c|c|}
\hline $\begin{array}{c}\mathrm{C}_{\text {DRUG }} \\
(\mathrm{M})\end{array}$ & $\begin{array}{c}\mathrm{FD}^{\mathrm{a}} \\
(\mathrm{M})\end{array}$ & $\begin{array}{c}\log [\mathrm{FD}] \\
(\mathrm{M})\end{array}$ & $\begin{array}{c}\Delta I \\
(\mathrm{~A})\end{array}$ & $\Phi$ \\
\hline $7.87 \mathrm{E}-05$ & $4.48 \mathrm{E}-06$ & -5.35 & $1.73 \mathrm{E}-07$ & -0.48 \\
\hline $9.83 \mathrm{E}-05$ & $1.01 \mathrm{E}-05$ & -5.00 & $2.06 \mathrm{E}-07$ & -0.38 \\
\hline $1.18 \mathrm{E}-04$ & $1.57 \mathrm{E}-05$ & -4.80 & $2.39 \mathrm{E}-07$ & -0.28 \\
\hline $1.38 \mathrm{E}-04$ & $2.13 \mathrm{E}-05$ & -4.67 & $2.72 \mathrm{E}-07$ & -0.20 \\
\hline $1.57 \mathrm{E}-04$ & $2.69 \mathrm{E}-05$ & -4.57 & $3.05 \mathrm{E}-07$ & -0.11 \\
\hline $1.97 \mathrm{E}-04$ & $3.81 \mathrm{E}-05$ & -4.42 & $3.71 \mathrm{E}-07$ & 0.05 \\
\hline $2.36 \mathrm{E}-04$ & $4.93 \mathrm{E}-05$ & -4.31 & $4.36 \mathrm{E}-07$ & 0.22 \\
\hline $2.75 \mathrm{E}-04$ & $6.05 \mathrm{E}-05$ & -4.22 & $5.02 \mathrm{E}-07$ & 0.41 \\
\hline $3.15 \mathrm{E}-04$ & $7.17 \mathrm{E}-05$ & -4.14 & $5.68 \mathrm{E}-07$ & 0.64 \\
\hline $3.93 \mathrm{E}-04$ & $9.41 \mathrm{E}-05$ & -4.03 & $7.00 \mathrm{E}-07\left(\Delta I_{\max }\right)$ & --- \\
\hline
\end{tabular}

a The concentration of free drug (FD) has been evaluated by considering the calibration curve obtained in the absence of albumin.

As apparent from Figure 3 and Figure S3, the $\Phi$ vs $\log [\mathrm{FD}]$ plot is not linear and the curve can be divided in two different linear sectors. Thus, the slopes of these two lines give the stoichiometries $\left(m_{1}\right.$ and $m_{2}$, these values have to be approximated to the nearest integer) of the complexes present in solution.

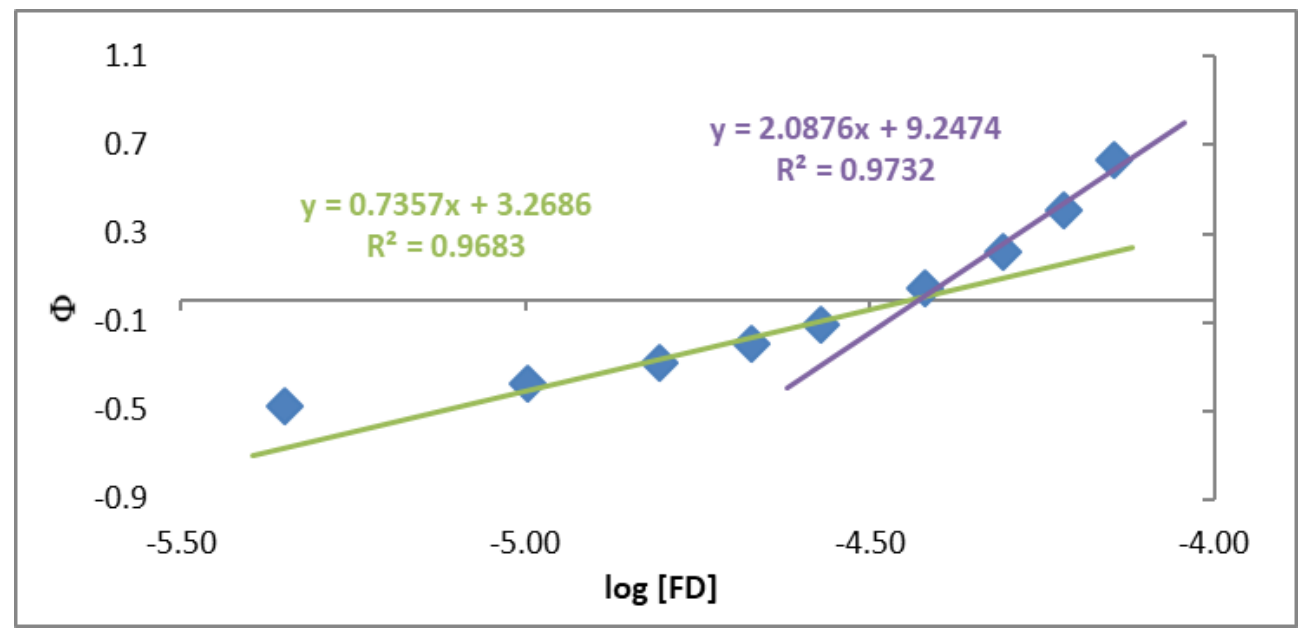

Figure S3. Relationship between $\Phi$ and $\log [\mathrm{FD}]$ in the case of ketoprofen with HS, exemplificative of the multiple complexes formation situation. The slopes of the two lines give the stoichiometries of the complexes present in solution.

On the other hand, the determination of the binding constants requires the further manipulation of the data reported in Table S4, in order to build the " $f_{1}$ vs [FD]" and the " $\Delta I$ vs Z" plots. The mathematical procedure behind the construction of these relationships has been detailed in the main text and the data obtained for the ketoprofen-HS situation are reported in Table S5. 
Table S5. Data employed for the construction of the " $f_{1}$ vs $[F D]$ " and the " $\Delta I$ vs $Z$ " plots in the case of the ketoprofen-HS complex; these data results from the manipulation of those reported in Table $\mathrm{S4}$.

\begin{tabular}{|c|c|c|c|}
\hline $\begin{array}{c}\Delta I \\
(\mathrm{~A})\end{array}$ & $\begin{array}{c}{[\mathrm{FD}]^{\mathrm{a}}} \\
(\mathrm{M})\end{array}$ & $f_{1}=\frac{\Delta I}{[\mathrm{FD}]}$ & $\mathrm{Z}=\frac{1}{[\mathrm{FD}]}$ \\
\hline $1.73 \mathrm{E}-07$ & $4.48 \mathrm{E}-06$ & $3.87 \mathrm{E}-02$ & $2.23 \mathrm{E}+05$ \\
\hline $2.06 \mathrm{E}-07$ & $1.01 \mathrm{E}-05$ & $2.05 \mathrm{E}-02$ & $9.92 \mathrm{E}+04$ \\
\hline $2.39 \mathrm{E}-07$ & $1.57 \mathrm{E}-05$ & $1.53 \mathrm{E}-02$ & $6.38 \mathrm{E}+04$ \\
\hline $2.72 \mathrm{E}-07$ & $2.13 \mathrm{E}-05$ & $1.28 \mathrm{E}-02$ & $4.70 \mathrm{E}+04$ \\
\hline $3.05 \mathrm{E}-07$ & $2.69 \mathrm{E}-05$ & $1.13 \mathrm{E}-02$ & $3.72 \mathrm{E}+04$ \\
\hline $3.71 \mathrm{E}-07$ & $3.81 \mathrm{E}-05$ & $9.74 \mathrm{E}-03$ & $2.63 \mathrm{E}+04$ \\
\hline $4.36 \mathrm{E}-07$ & $4.93 \mathrm{E}-05$ & $8.86 \mathrm{E}-03$ & $2.03 \mathrm{E}+04$ \\
\hline $5.02 \mathrm{E}-07$ & $6.05 \mathrm{E}-05$ & $8.31 \mathrm{E}-03$ & $1.65 \mathrm{E}+04$ \\
\hline $5.68 \mathrm{E}-07$ & $7.17 \mathrm{E}-05$ & $7.93 \mathrm{E}-03$ & $1.40 \mathrm{E}+04$ \\
\hline $7.00 \mathrm{E}-07$ & $9.41 \mathrm{E}-05$ & $7.44 \mathrm{E}-03$ & $1.06 \mathrm{E}+04$ \\
\hline
\end{tabular}

${ }^{a}$ The concentration of free drug (FD) has been evaluated by considering the calibration curve obtained in the absence of albumin.

The resulting " $f_{1}$ vs $[\mathrm{FD}]$ ” and the " $\Delta I$ vs Z" plots are reported in Figures S4 and S5, respectively. Since the determination of the relevant $\beta$ values requires to know the intercept with the ordinate axis and the slope of the tangent to the curves, these have been fitted with a polynomial regression of $6^{\text {th }}$ grade, offering a very good fitting in the region approaching the ordinate axis (small $\mathrm{x}$-values). It is worth noting that the use of a $6^{\text {th }}$ grade polynomial regression is a good compromise in terms of fitting of the data in the small $\mathrm{x}$-values region. This gives a very easy-to-handle equation (see below) and the fluctuations observed at high $\mathrm{x}$-values do not affect the obtained results.

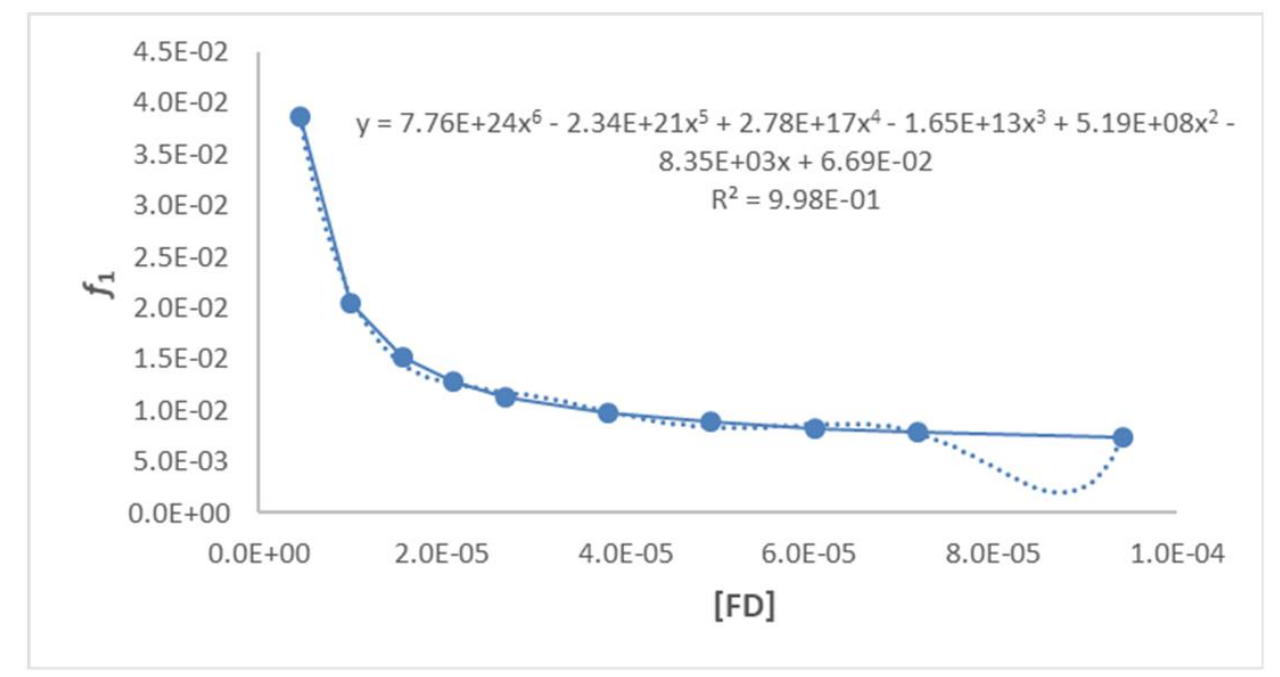

Figure S4. Relationship between $f_{1}$ and [FD] in the case of ketoprofen with HS. The last two terms of the regression represent, respectively $a_{1}$ (coefficient of $x$ ) and $a_{2}$ (known term). 


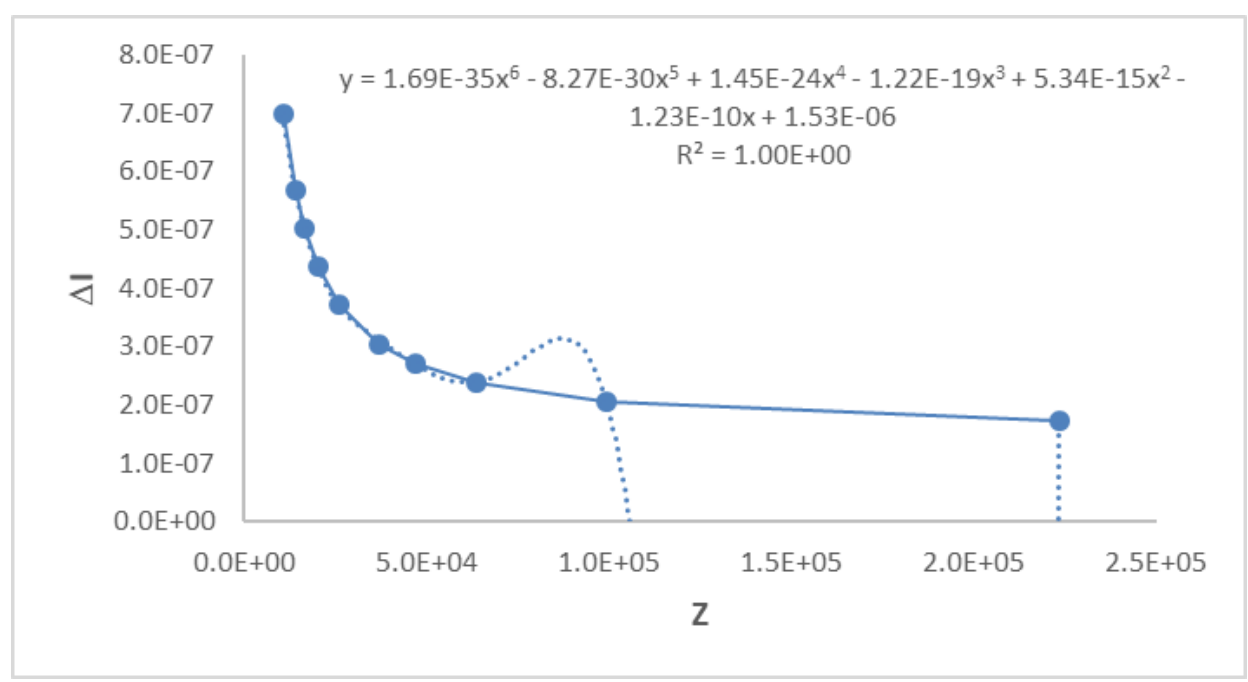

Figure S5. Relationship between $\Delta I$ and $\mathrm{Z}$ in the case of ketoprofen with HS. The last two terms of the regression represent, respectively $b_{1}$ (coefficient of $x$ ) and $b_{2}$ (known term).

By considering the last two terms (coefficient of $\mathrm{x}$ and known term) of the resulting polynomial regressions, it is possible to extrapolate $a_{1}, a_{2}, b_{1}$ and $b_{2}$, namely the data required for the determination of $\beta_{1}$ and $\beta_{2}$, according to the mathematical procedure reported in the main text.

\section{S.4 Determination of the Free Drug Fraction and Competition for the Drug Complexing Sites by Sulfanilamide.}

The free drug fraction can be calculated from the ratio of the current intensity $(I)$ for a certain drug concentration (typically $10^{-5} \mathrm{M}$ ) in the presence of albumin $\left(I_{\mathrm{FD}}\right)$ with respect to the signal obtained from the same drug concentration in the presence of the supporting electrolyte $(\mathrm{NaCl} 0.9 \%)$ only $\left(I_{\mathrm{TD}}\right)$. In this experiment, the concentration of albumin is in the physiological range, as to obtain realistic values. The adopted equations are reported below:

$\%$ free drug $=\frac{I_{\mathrm{FD}}}{I_{\mathrm{TD}}} \cdot 100$

$\%$ bound drug $=1-\%$ free drug $=\frac{I_{\mathrm{TD}}-I_{\mathrm{FD}}}{I_{\mathrm{TD}}} \cdot 100$ 
For studying the competition of sulfanilamide for the same complexation sites of albumin, a further series of voltammogramms were obtained in the presence of albumin, supporting electrolyte and $10^{-5} \mathrm{M}$ sulfanilamide. The free drug fraction is further evaluated according to the above reported formula, and from the difference of the two percentage fractions of free drug (in the presence and absence of sulfanilamide), the \% amount of drug displaced by sulfanilamide is obtained. The adopted equation is reported below:

$$
\% \text { displaced drug }=\frac{I_{\mathrm{S}}-I_{\mathrm{FD}}}{I_{\mathrm{FD}}} \cdot 100
$$

